\title{
Research Paper: A Comparison of Self-Compassion and Self-Esteem Based on Their Relationship With Adaptive and Maladaptive Emotion Regulation Strategies
}

\author{
Zahra Kamalinasab $^{1}$, Parvaneh Mohammadkhani ${ }^{2}$
}

1. Department of Psychology, Faculty of Psychology and Social Sciences, Central Tehran Branch, Islamic Azad University, Tehran, Iran

2. Department of Clinical Psychology, University of Social Welfare and Rehabilitation Sciences, Tehran, Iran.

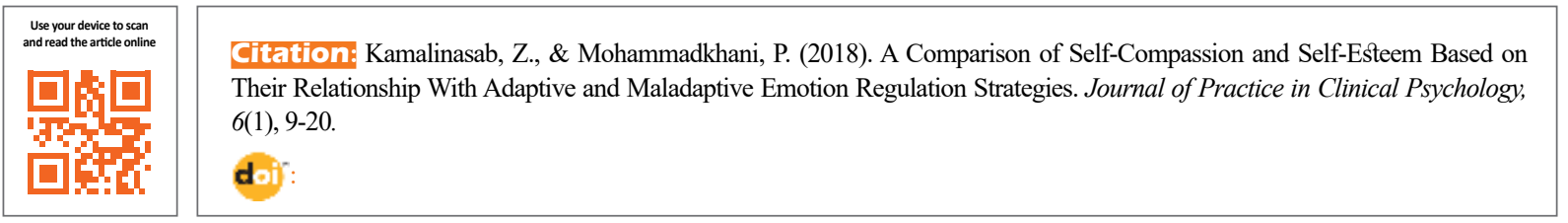

Article info:

Received: 11 Jun. 2017

Accepted: 31 Oct. 2017
Keywords:

Empathy, Emotion, Regulation

\section{ABSTRACT}

Objective: The purpose of this study was to investigate the relationship between adaptive and maladaptive cognitive emotion regulation strategies, self-compassion, and self-esteem; and to determine whether self-compassion compared to self-esteem, was a better predictor of the scores on the adaptive and maladaptive cognitive emotion regulation strategies.

Methods: This was a cross-sectional study. The statistical population included all students of the University of Applied Science and Technology (unit 47 in Tehran), in the education year 2015-2016. A total of 146 students were selected using a convenient sampling method. After explaining the purpose and procedure of the study to the participants and obtaining their verbal consent, the following questionnaires were administered: The Rosenberg Self-Esteem Scale, the Self-Compassion Scale, and the Cognitive Emotion Regulation Questionnaire. Pearson correlation coefficient, two variable and multivariable regression analyses were used to analyze the data. All analyses were performed using SPSS software version 17.

Results: The results indicated that both self-compassion and self-esteem were positively related to adaptive and negatively related to maladaptive cognitive emotion regulation strategies. Regression analysis revealed that self-compassion was a better predictor of maladaptive strategies, and self-esteem was a better predictor of adaptive strategies.

Conclusion: Self-compassion is a good indicator of mental health. In some aspects, selfcompassion relative to self-esteem, is a better predictor of mental health. It also contains some healthy aspects of self-esteem. Therefore, teaching self-compassion skills to therapists and patients can be a useful technique to improve the mental health of the society.

\section{Introduction}

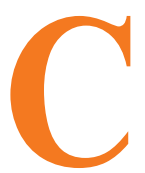

onflict, failure, loss, and stress have always been present in the history of human evolution. Frequent dealing with such incidents has led to the formation of emotions, or specific psychological adaptations that integrate our cognitive system (Tooby \& Cosmides, 2005). We, human beings, have an extraordinary ability to regulate emotions resulting from these incidents. These regula-

\section{* Corresponding Author:}

Parvaneh Mohammadkhani, PhD

Address: Department of Clinical Psychology, University of Social Welfare and Rehabilitation Sciences, Tehran, Iran.

Tel: +98 (21) 22180045

E-mail:parmohamir@yahoo.com 
tory efforts can significantly determine the impacts of these unpleasant events on our health and well-being (Oschsner \& Gross, 2005). Emotion regulation refers to a process through which people present their emotions as a response to environmental demands (Bargh \& Williams, 2007, as cited in Goodal, 2015). In addition, although emotions are felt at an individual level, emotion regulation, as a wider concept, includes mechanisms that can regulate one's social environment (Shuman, Wagner, Walter \& Scherer, 2014). Among the most common emotion regulation strategies are cognitive ones. Cognitive emotion regulation strategies are cognitive responses to emotion-eliciting events that are used consciously or unconsciously, to regulate emotional experiences (Bargh \& Williams, 2007; Rottenberg \& Gross, 2007).

Moreover, adaptive cognitive emotion regulation strategies are as follows: acceptance (thoughts of accepting a negative event and resigning yourself to it); positive refocusing (thinking about positive events instead of thinking about the negative event); refocus on planning (thinking about how to deal with the negative event or thinking about a plan to change the situation); positive reappraisal (thoughts of giving a positive meaning to the negative event, thinking about how the event can make you stronger, or searching for positive aspects of an event); putting into perspective (playing down the severity of the event or emphasizing on its relativity compared to other events).

Maladaptive cognitive emotion regulation strategies include: self-blame (thoughts of blaming yourself for negative experiences); blaming-others (thoughts of putting the blame of the negative event on others); catastrophizing (thoughts of focusing on the terror of the experience or thinking that the negative event is the worst thing that could happen to you); rumination (constantly thinking about the feelings and thoughts accompanied with the unpleasant event, without trying to modify the environment) (Garnefski, Teerds, Kraaij, Legerstee, \& Van Den Kommer, 2004). Sharifi Bastan, Yazdi, and Zahraei (2016) showed that among the cognitive emotion regulation strategies, positive reappraisal, self-blame, putting into perspective, and refocus on planning predicted $65 \%$ of the variance of resilience in the first step, but positive and negative effects did not significantly predict resilience. Salehi, Mazaheri, Aghajani, and Jahanbazi (2015) also found that among the cognitive emotion regulation strategies, catastrophizing, acceptance, refocus on planning, and rumination along with recent stress had an impact on depression and significantly predicted it.

Self-compassion and self-esteem are two constructs that may influence the use of adaptive and maladap- tive cognitive emotion regulation strategies. Theoretical works in the area of self-esteem started in the last century with the work of James (1892). James (1892) defined self-esteem as one's perception of their own competencies in a valuable domain. Leary \& Downs (1995) defined self-esteem as an internal gauge, designed by natural selection that evaluates and monitors one's success in inter-personal relationships. Self-compassion and self-esteem are, in fact, strategies that help us avoid our negative feelings, but self-compassion has some advantages over self-esteem.

It has been pointed out in many psychological theories that, while trying to maintain positive feelings, we often form misconceptions in favor of ourselves. These misconceptions are unconsciously accompanied by negative evaluation of others and some levels of self-deception. These false opportunistic conceptions cannot alone improve our ability to accurately see ourselves and others and also cannot assist us in facing the undeniable evidence that we have weak points. But in self-compassion, without these false beliefs and defensiveness, there is a right understanding of personal qualities, whether good or bad. Recognizing weak points is healthier for us than denying them, because it helps us accept them compassionately and take effective behavioral steps to modify them (Saeedi, Ghorbani, Sarafraz \& Sharifian, 2013).

Individuals with high self-compassion tend to have better psychological health because with self-compassion, the unavoidable pain and feeling of failure that all individuals may experience is not continued due to a cruel self-blame, feeling of isolation, and excessive identification with thoughts and emotions. This supportive attitude toward self is related to many positive psychological outcomes, such as higher motivation for solving interpersonal conflicts, constructive problem-solving, marital life stability, readiness to experience less shame, less negative self-evaluation, less neurotic perfectionism, and higher life satisfaction; in addition, self-compassion is significantly related to having compassion toward others (Neff \& Pommier, 2013).

On the other hand, self-compassion is a better alternative to self-esteem. Self-compassion includes having compassion and caring for oneself in the face of perceived difficulties or incompetency (Bennett-Goleman, 2002). Neff (2003a; 2003b) defines self-compassion as a construct having three essential components: self-kindness versus self-judgment, feelings of common humanity versus isolation, and mindfulness versus over-identification. When faced with pain, incompetency, or failure, those with self-compassion, instead of exaggerating the 
pain or suffering, and blaming themselves, act toward themselves warmly and without making judgments. This process also includes the understanding that being incomplete, making mistakes, and facing life problems are parts of common experiences of all human beings, and the person is not the only one who is experiencing them. Self-compassion also requires a balanced approach toward negative experiences, so that negative experiences are neither suppressed nor exaggerated (Neff, 2003a).

Based on what was said, self-compassion that is based on the feelings of importance, caring, and nonjudgmental understanding is distinct from self-esteem, which is based on positive self-evaluation (Neff, 2003a). Evaluation anxiety can increase the elicitation of emotions, such as shame that results from a negative self-evaluation and perceiving the danger of social isolation (Tangney, 2003). Self-compassion may reduce self-evaluation anxiety (Neff, 2008). Gilbert (2005), drawing from the social mentality theory, suggests that self-compassion deactivates the threat system (the system related to feelings of insecurity, defensiveness, and limbic system) and activates the soothing system (the system related to secure attachment, security, and the oxytocin system). In contrast, self-esteem is based on superiority/inferiority evaluation and is related to activation of dopamine (Gilbert \& Irons, 2005). The soothing quality of self-compassion leads to a higher capacity for intimacy, effective emotion regulation, and a better adjustment to the environment (Gilbert, 2005). Self-compassion can be considered as an adaptive emotion regulation strategy that requires a conscious awareness of emotions and avoiding suppression of emotions or distancing from them (Neff, 2003a).

Since emotion regulation may play an important role in initializing, increasing, keeping, or decreasing positive and negative emotions in response to environment, it enables people to regulate and express emotions, which has a pivotal role in all aspects of human functioning and plays a critical role in the way people cope with stressful events and experience happiness (Fosca, 2008). In addition, emotion regulation is accompanied by higher mental ability to process social information; therefore, those with higher capacity for emotion regulation are more successful in the face of psychological and social pressures (Firoozi, 2010).

The present study is aimed at increasing the knowledge of readers, especially students, in terms of emotion regulation. In fact, if people get more knowledgeable about emotion regulation and its strategies, they become more able to manage and control their own emotions, such as anger, stress, anxiety, etc. On the other hand, self-com- passion and self-esteem are adaptive constructs; considering the different nature of the two constructs, it is predicted that self-compassion has a positive role in regulating and managing negative emotions and improved use of adaptive emotion regulation strategies, thereby improving individuals' mental health.

Given that self-compassion is a new concept in psychology and considering its importance in optimal mental performance, the present study is aimed at examining the relationship between self-compassion and self-esteem with adaptive and maladaptive cognitive emotion regulation strategies. The present study also aims to explore whether self-compassion, compared to self-esteem, is more related to adaptive cognitive emotion regulation strategies. In other words, we want to determine which of the two constructs, self-compassion and self-esteem, is a better predictor of using adaptive and maladaptive cognitive emotion regulation strategies.

\section{Methods}

This is a cross-sectional study. The statistical population included all students of the University of Applied Science and Technology (Unit 47 of Tehran), in the education year 2015-2016; a total of 146 students were selected from this population, using a convenient sampling method. After primary analyses and examining the outliners, 15 participants were excluded from the study. The statistical analysis was conducted on the remaining 131 participants. The inclusion criteria were as follows: informed consent for participation in the study and no history of medical or psychiatric disorders, requiring the use of medications during the study. The study sample consists of 67 women, 61 men, and 3 people, who did not reveal their gender. The mean age of the participants was 31.56 , with a range from 18 to 60 years.

The researcher approached students on the campus or in some cases, inside classrooms, and after explaining to them how to complete the questionnaires and obtaining their verbal consent, the study questionnaires were administered. It took 15 to 20 minutes for participants to complete the questionnaires. The Pearson correlation coefficient and two-variable and multivariable regression analyses were used to analyze the data. All analyses were performed using SPSS software version 17.

The Rosenberg Self-Esteem Scale (RSES) was created by Rosenberg in 1965. This instrument has 10 items that are rated on a 4-point scale ranging from strongly agree to strongly disagree. This scale assesses the overall selfesteem based on statements from respondents regarding 
positive and negative feelings. Previous studies have reported alpha coefficients ranging from 0.72 to 0.88 for the scale (Gray Little, Williams, \& Hancock, 1997). A 7-week test-retest reliability of 0.61 was also obtained for the scale (Byrne, 1983). In an Iranian sample, the reliability of the RSES was reported to be good (Yamini \& Tahriri, 2005). In addition, in a study by Joshanloo \& Ghaedi (2008), a Cronbach's alpha of 0.83 was reported for the RSES. In the present study, a Cronbach's alpha of 0.76 was obtained for the scale.

The Self-Compassion Scale (SCS) was created by Neff in 2003 it has 26 items that are rated on a 5-point scale, ranging from almost never (1) to almost always (5) (Neff, 2003b). Respondents are asked to reveal how they act toward themselves in difficult situations. This scale assesses three components with six subscales, including self-kindness versus self-judgment, feelings of common humanity versus isolation, and mindfulness versus over-identification. Research studies have shown good convergent validity (Neff, Kirkpatrick, \& Rude, 2007), discriminant validity, internal consistency, and test-retest reliability (Neff, 2003b) of the SCS. In an Iranian sample, a Cronbach's alpha of 0.84 was reported for the scale, indicating its good internal consistency (Ghorbani, Watson, Chen, \& Norballa, 2012). In the present study, a Cronbach's alpha of 0.71 was obtained for the SCS.

The Cognitive Emotion Regulation Questionnaire (CERQ) is a multidimensional questionnaire, developed by Garnefski, Kraaij, \& Spinhoven (2001) and designed to assess coping strategies used by a person after experiencing negative life events. It is a self-report instrument and includes 36 items and 9 subscales. Garnefski et al. (2002) have reported Cronbach's alphas of 0.91, 0.86, and 0.93 for the total scale, adaptive strategies, and maladaptive strategies, respectively. Besharat \& Bazzazian (2014) reported good psychometric properties, including internal consistency, test-retest reliability, content validity, convergent validity, and divergent validity, for the CERQ. In addition, in a sample of the general population (171 men, 97 women, $n=386$ ), Besharat (2009) reported Cronbach's alphas ranging from 0.67 to 0.89 for the subscales of the CERQ. Hassani (2010) also found good internal consistency for all the 9 subscales of the questionnaire; Cronbach's alphas ranged from 0.76 to 0.93. In the present study, a Cronbach's alpha of 0.79 was obtained for the CERQ.

\section{Results}

First, the assumptions of normality, linearity, and homoscedasticity were examined; no violation of assump- tions was found. In the primary analyses and an examination of the outliners and abnormal data, 15 participants were removed from the study. The pairwise method was used for missing data; participants were excluded if they had missing data for a particular analysis, but they were included in all the analyses for which they had the required data. Participants comprised of 67 women, 61 men, and 3 individuals, who did not state their gender. The mean age of the participants was 31.56, ranging from 18 to 60 years. $61 \%$ of the participants had an associate's degree and $31 \%$ had a bachelor's degree $(8 \%$ missing data).

The Pearson correlation coefficient $(\mathrm{N}=122)$ was used to examine the relationship between self-esteem, selfcompassion, and adaptive and maladaptive cognitive emotion regulation strategies; the results are shown in Table 1. As you can see in the total correlation matrix, self-esteem has a relatively strong positive relationship with adaptive strategies and a negative relationship with maladaptive strategies. A relatively stronger positive correlation is seen between self-esteem and positive reappraisal subscale, showing $23 \%$ common variance between the two variables. In addition, as you can see in Table 1, self-compassion is positively related to adaptive cognitive emotion regulation strategies and negatively related to maladaptive ones. To be precise, self-compassion is negatively related to catastrophizing and positively related to positive refocusing and refocus on planning.

Two-variable and multivariable regression analyses with the Enter method were used to examine the relationship of self-esteem and self-compassion with adaptive and maladaptive cognitive emotion regulation strategies. Before conducting the analyses, the assumptions of normality, linearity, and homoscedasticity were examined, and no violation of assumptions was observed. The results of regression analyses are presented in Tables 2, 3, and 4

The results of two-variable regression analysis between self-esteem and maladaptive cognitive emotion regulation strategies showed that self-esteem can predict rumination $\left(\mathrm{P}<0.001 \& \mathrm{~F}_{(1.121)}=10.365\right)$ and catastrophizing $\left(\mathrm{P}<0.001 \& \mathrm{~F}_{(1.121)}=13.777\right)$, and explains $7.9 \%$ and $15.2 \%$ of the total variance of these variables, respectively. The results of two-variable regression analysis between self-esteem and adaptive cognitive emotion regulation strategies $(\mathrm{N}=123)$, showed that self-esteem can predict positive refocusing $\left(\mathrm{P}<0.001 \& \mathrm{~F}_{(1.121)}=26.48\right)$, refocus on planning $\left(\mathrm{P}<0.001 \& \mathrm{~F}_{(1.121)}=29.367\right)$, positive reappraisal $\left(\mathrm{P}<0.001 \& \mathrm{~F}_{(1.121)}=36.906\right)$, and putting into perspective $\left(\mathrm{P}<0.001 \& \mathrm{~F}_{(1.121)}=9.101\right)$, and explains 
Table 1. Correlation matrix of self-compassion, self-esteem, and adaptive and maladaptive cognitive emotion regulation strategies $(\mathrm{N}=123)$

\begin{tabular}{|c|c|c|c|c|c|c|c|c|c|c|c|c|}
\hline & & 1 & 2 & 3 & 4 & 5 & 6 & 7 & 8 & 9 & 10 & 11 \\
\hline 1 & Self-blame & 1 & & & & & & & & & & \\
\hline 2 & Acceptance & $0.344^{* *}$ & 1 & & & & & & & & & \\
\hline 3 & Rumination & $0.411^{* *}$ & $0.416^{* *}$ & 1 & & & & & & & & \\
\hline 4 & $\begin{array}{l}\text { Positive refo- } \\
\text { cusing }\end{array}$ & 0.050 & -0.048 & -0.071 & 1 & & & & & & & \\
\hline 5 & $\begin{array}{l}\text { Refocus on } \\
\text { planning }\end{array}$ & 0.008 & 0.044 & 0.100 & $0.649^{* *}$ & 1 & & & & & & \\
\hline 6 & $\begin{array}{l}\text { Positive reap- } \\
\text { praisal }\end{array}$ & 0.045 & 0.094 & -0.107 & $0.557^{* *}$ & $0.609^{* *}$ & 1 & & & & & \\
\hline 7 & $\begin{array}{l}\text { Putting into } \\
\text { perspective }\end{array}$ & -0.012 & $0.192^{*}$ & 0.062 & $0.397^{* *}$ & $0.437^{* *}$ & $0.498^{* *}$ & 1 & & & & \\
\hline 8 & Catastrophizing & $0.361^{* *}$ & $0.241^{* *}$ & $0.434^{* *}$ & -0.127 & -0.134 & $-0.182^{*}$ & 0.052 & 1 & & & \\
\hline 9 & Blaming others & 0.005 & 0.020 & $0.226^{* *}$ & -0.086 & 0.033 & -0.071 & 0.131 & $0.387^{* *}$ & 1 & & \\
\hline 10 & $\begin{array}{l}\text { Self-compas- } \\
\text { sion }\end{array}$ & $-0.310^{* *}$ & $-0.202^{*}$ & $-0.355^{* *}$ & $0.426^{* *}$ & $0.397^{* *}$ & $0.392^{* *}$ & $0.221^{*}$ & $-0.491^{* *}$ & $-0.190^{*}$ & 1 & \\
\hline 11 & Self-esteem & -0.133 & -0.172 & $-0.281^{* *}$ & $0.424^{* *}$ & $0.442^{* *}$ & $0.483^{* *}$ & $0.264^{* *}$ & $-0.320^{* *}$ & -0.078 & $0.528^{* *}$ & 1 \\
\hline
\end{tabular}

$* \mathrm{P}<0.05 ; * * \mathrm{P}<0.01$

CLINICAL PEYCH MLOGY

$18 \%, 19 \%, 23 \%$, and $7 \%$ of the total variance of these variables, respectively.

The results of multivariate regression analysis between self-compassion and adaptive cognitive emotion regulation strategies showed that self-compassion can predict positive refocusing $\left(\mathrm{P}<0.001 \& \mathrm{~F}_{(6.124)}=5.424\right)$, refocus on planning $\left(\mathrm{P}<0.001 \& \mathrm{~F}_{(6.124)}=4.932\right)$, positive reappraisal $\left(\mathrm{P}<0.001 \& \mathrm{~F}_{(6.124)}=4.936\right)$, and putting into perspective $\left(\mathrm{P}<0.001 \& \mathrm{~F}_{(6.124)}=3.759\right)$, and explains $20 \%, 19 \%, 19 \%$, and $15 \%$ of the total variance of these variables, respectively. The results also indicated that self-compassion can predict all the four maladaptive strategies. Among self-compassion subscales, identification has a unique and significantly negative role in the equation of self-blame ( $\mathrm{P}<0.05)$, and catastrophizing $(\mathrm{P}<0.05)$ and self-kindness have unique and significantly positive roles in the equation of blaming others $(\mathrm{P}<0.05)$. Overall, self-compassion explains 16\%, 22\%, 29\%, and $5 \%$ of the total variance of self-blame, rumination, catastrophizing, and blaming others, respectively.

As you can see in Table 5, self-compassion predicts all the four maladaptive cognitive emotion regulation strategies; self-esteem predicts two maladaptive cognitive emotion regulation strategies, i.e. rumination and catastrophizing. The results of this analysis indicate that self-compassion, compared to self-esteem, is more capable of predicting different maladaptive cognitive emotion regulation strategies. Self-compassion negatively

Table 2. The results of two-variable regression analysis for self-esteem and cognitive emotion regulation strategies

\begin{tabular}{|c|c|c|c|c|c|c|c|c|c|}
\hline Self-esteem & $\begin{array}{c}\text { Self- } \\
\text { Blame }\end{array}$ & $\begin{array}{l}\text { Rumina- } \\
\text { tion }\end{array}$ & $\begin{array}{l}\text { Cata- } \\
\text { stroph- } \\
\text { izing }\end{array}$ & $\begin{array}{l}\text { Blaming } \\
\text { Others }\end{array}$ & Acceptance & $\begin{array}{c}\text { Positive } \\
\text { Refocusing }\end{array}$ & $\begin{array}{c}\text { Refocus } \\
\text { on Plan- } \\
\text { ning }\end{array}$ & $\begin{array}{c}\text { Positive Re- } \\
\text { appraisal }\end{array}$ & $\begin{array}{l}\text { Putting Into } \\
\text { Perspective }\end{array}$ \\
\hline \multicolumn{10}{|c|}{ Self-Esteem } \\
\hline R square & 0.018 & 0.079 & 0.102 & 0.006 & 0.030 & 0.180 & 0.195 & 0.234 & 0.070 \\
\hline Sig. & 0.141 & $0.002^{*}$ & $0.000^{* *}$ & 0.390 & 0.057 & $0.000^{* *}$ & $0.000^{* *}$ & $0.000^{* *}$ & $0.003^{*}$ \\
\hline$F_{(1.121)}$ & 2.195 & 10.365 & 13.777 & 0.745 & 3.688 & 26.489 & 29.367 & 36.906 & 9.101 \\
\hline Beta & -0.133 & -0.281 & -0.320 & -0.078 & -0.172 & 0.426 & 0.442 & 0.483 & 0.264 \\
\hline
\end{tabular}

$* \mathrm{P}<0.05 ; * * \mathrm{P}<0.01$ 
Table 3. The results of multivariate regression analysis between self-compassion and maladaptive cognitive emotion regulation strategies

\begin{tabular}{|c|c|c|c|c|c|}
\hline \multicolumn{2}{|c|}{ Maladaptive Strategies } & Self-Blame & Rumination & Catastrophizing & Blaming Others \\
\hline \multirow{3}{*}{ Complete model } & R Square & 0.163 & 0.236 & 0.293 & 0.053 \\
\hline & Sig. & $0.001^{* *}$ & $0.000^{* * *}$ & $0.000^{* * *}$ & $0.046^{*}$ \\
\hline & $\mathrm{F}_{(6.124)}$ & 4.011 & 6.385 & 8.555 & 2.212 \\
\hline \multirow{2}{*}{ Self-kindness } & Sig. & 0.755 & 0.804 & 0.719 & $0.039^{*}$ \\
\hline & Beta & 0.033 & -0.025 & 0.034 & 0.226 \\
\hline \multirow{2}{*}{ Self-judgment } & Sig. & 0.707 & 0.921 & 0.942 & 0.818 \\
\hline & Beta & -0.045 & -0.011 & 0.008 & 0.029 \\
\hline \multirow{2}{*}{ Humanity } & Sig. & 0.290 & 0.601 & 0.461 & 0.171 \\
\hline & Beta & -0.099 & 0.047 & -0.063 & -0.133 \\
\hline \multirow{2}{*}{ Isolation } & Sig. & $0.030^{*}$ & 0.409 & $0.037^{*}$ & 0.788 \\
\hline & Beta & -0.283 & 0.102 & -0.249 & -0.036 \\
\hline \multirow{2}{*}{ Mindfulness } & Sig. & 0.213 & 0.865 & 0.289 & 0.285 \\
\hline & Beta & 0.136 & -0.018 & -0.106 & -0.121 \\
\hline \multirow{2}{*}{ Identification } & Sig. & 0.213 & $0.000^{* * *}$ & $0.022^{*}$ & 0.126 \\
\hline & Beta & -0.167 & -0.531 & -0.285 & -0.213 \\
\hline
\end{tabular}

predicts self-blame, rumination, and blaming others and positively predicts catastrophizing. In addition, selfcompassion can predict all the five maladaptive cognitive emotion regulation strategies, and self-esteem can positively predict four adaptive strategies, i.e., positive refocusing, refocus on planning, positive reappraisal, and putting into perspective. Self-compassion negatively predicts acceptance and positively predicts positive refocusing, refocus on planning, positive reappraisal, and putting into perspective. According to Beta values, selfesteem relative to self-compassion, is a better predictor of refocus on planning (Beta $=0.298$ ), positive reappraisal $(B e t a=0.376)$, and putting into perspective $($ Beta $=0.220)$.

\section{Discussion}

According to the study findings, self-esteem is positively related to adaptive and negatively related to maladaptive cognitive emotion regulation strategies. This finding is consistent with those of Paradise and Kernis (2002), Freire and Tavares (2011), Dogan, Totan, and Sapmaz (2013), Zare and Najafi (2007), Afshary, Babakhani, Ahmadi, Shamseddinilorry (2016), Forrester, Slater, Jomar,
Mitzman \& Taylor (2017), and Alavinezhad, Mousavia and Sohrabib (2014), regarding the significant association of self-esteem with self-regulation. These researchers showed that higher scores on self-esteem are related to higher levels of psychological well-being. In addition, they found that self-esteem has a stronger association with mental health indicators and happiness than emotion regulation strategies. They also showed the mediating role of self-esteem in the relationship between psychological well-being, emotional self-efficacy, and emotional balance with happiness and found that high self-esteem reduces suicidal behavior, self-inflammation, anger, and aggression in those with clinical conditions. However, this finding is not consistent with those of Bushman \& Baumeister (1998); Sedikides (1993); Aberson, Healy \& Romero (2000); Bushman \& Thomaes (2011); Cramer and Jones (2008) and Peyvastegar, Yazdi \& Mokhtari (2011). They showed that aggression is higher in narcissistic people with a high level of self-esteem (grandiose narcissism). There are discrepant findings about the relationship between self-esteem and aggression; some studies have shown that as self-esteem decreases, aggression also decreases. 
Table 4. The results of multivariate regression analysis between self-compassion and adaptive cognitive emotion regulation strategies

\begin{tabular}{|c|c|c|c|c|c|c|}
\hline Adaptive Strateg & $\begin{array}{l}\text { gies } \\
\text { Self-Compassion }\end{array}$ & Acceptance & $\begin{array}{l}\text { Positive Refo- } \\
\text { cusing }\end{array}$ & $\begin{array}{c}\text { Refocus on } \\
\text { Planning }\end{array}$ & $\begin{array}{c}\text { Positive Reap- } \\
\text { praisal }\end{array}$ & $\begin{array}{l}\text { Putting Into } \\
\text { Perspective }\end{array}$ \\
\hline \multirow{3}{*}{ Complete model } & R Square & 0.076 & 0.208 & 0.193 & 0.193 & 0.154 \\
\hline & Sig. & 0.127 & $0.000^{* * *}$ & $0.000^{* * *}$ & $0.000^{* * *}$ & $0.002^{* *}$ \\
\hline & $F_{(6.124)}$ & 1.699 & 5.424 & 4.932 & 4.936 & 3.759 \\
\hline \multirow{2}{*}{ Self-kindness } & Sig. & 0.896 & $0.040^{*}$ & $0.024^{*}$ & 0.319 & 0.052 \\
\hline & Beta & 0.014 & 0.209 & 0.234 & 0.102 & 0.205 \\
\hline \multirow{2}{*}{ Self-judgment } & Sig. & 0.555 & 0.879 & 0.228 & 0.705 & 0.414 \\
\hline & Beta & -0.074 & -0.018 & 0.142 & -0.045 & -0.098 \\
\hline \multirow{2}{*}{ Humanity } & Sig. & 0.884 & 0.520 & 0.479 & 0.277 & $0.010^{*}$ \\
\hline & Beta & -0.014 & 0.058 & 0.065 & 0.100 & 0.243 \\
\hline \multirow{2}{*}{ Isolation } & Sig. & 0.819 & 0.583 & 0.623 & 0.475 & 0.964 \\
\hline & Beta & -0.031 & 0.069 & 0.062 & -0.090 & 0.007 \\
\hline \multirow{2}{*}{ Mindfulness } & Sig. & 0.775 & 0.082 & 0.161 & 0.097 & 0.671 \\
\hline & Beta & 0.033 & 0.186 & 0.150 & 0.178 & 0.047 \\
\hline \multirow{2}{*}{ Identification } & Sig. & 0.070 & 0.589 & 0.590 & $0.012^{*}$ & 0.877 \\
\hline & Beta & -0.256 & 0.070 & -0.071 & 0.334 & 0.021 \\
\hline
\end{tabular}

${ }^{*} \mathrm{P}<0.05 ; * * \mathrm{P}<0.01 ; * * * \mathrm{P}<0.001$

that reduction of self-esteem in narcissistic individuals decreases their anger and negative emotional acting out.

Due to having an unreal self-esteem, reduction of selfsocial problems. In addition, some studies have shown Table 5 . The results of multivariate regression analysis between self-compassion, self-esteem, and adaptive cognitive emotion
regulation strategies

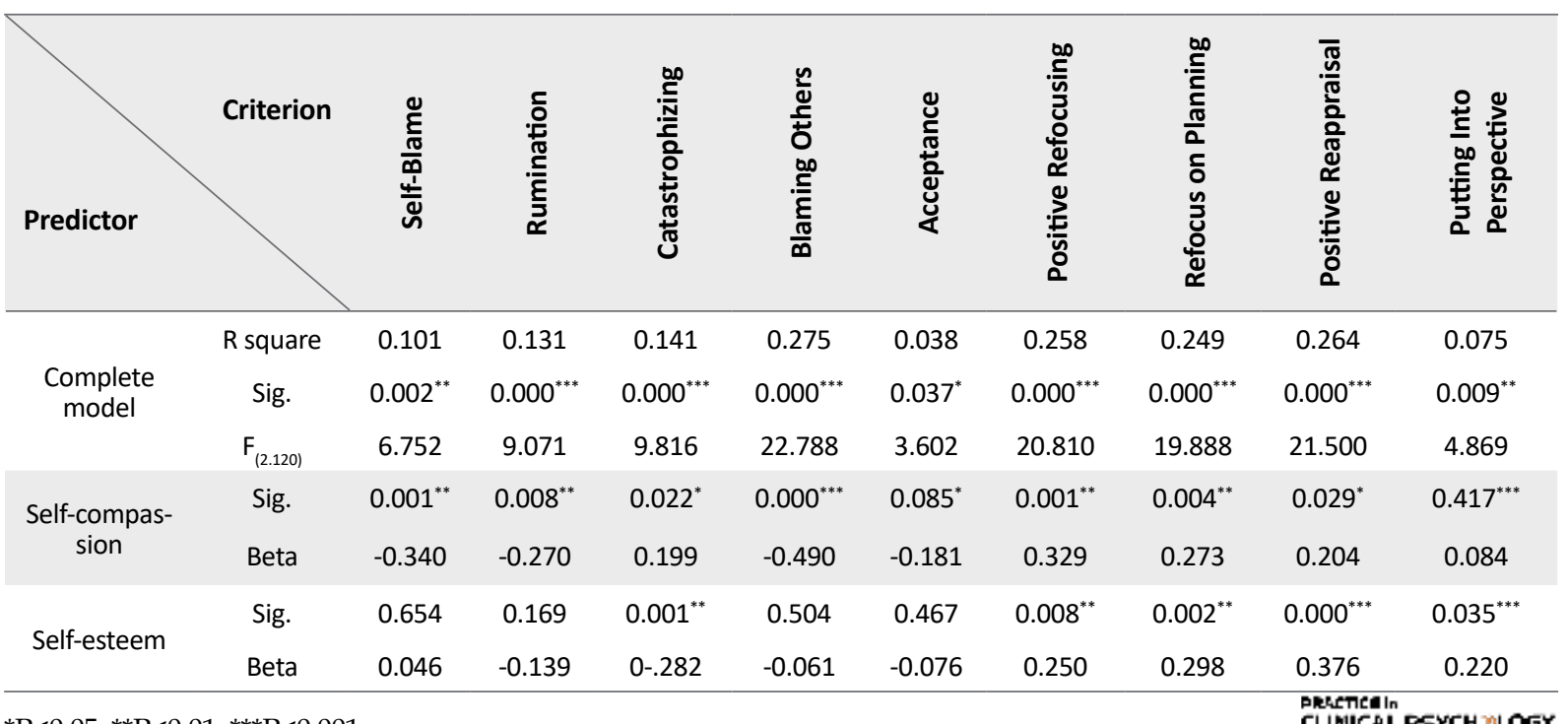


esteem can reduce anger in narcissistic individuals. Cramer and Jones (2008) have pointed out that those with high levels of self-esteem and narcissism show the highest level of aggression while receiving negative criticism from others. Therefore, high unreal self-esteem is negatively related to the use of cognitive emotion regulation strategies and is the best predictor of aggression (Peyvastegar, Yazdi, and Mokhtari, 2011).

In addition, the study results indicated that self-compassion is positively related to adaptive and negatively related to maladaptive strategies of cognitive emotion regulation. This finding is in line with those of Neff (2003a, 2009); Aalsma, Lapsley, and Flannery (2006); Gilbert (2005); Gilbert and Procter (2006); Welp \& Brown (2013); and Wang, Chen, Poon \& Jin (2016). They concluded that there are significant relationships between self-compassion and other mental health indicators that self-compassion is related to components of psychological well-being, such as happiness, optimism, personal initiative, and sociability, and that self-compassion decreases anxiety, depression, neurotic perfectionism, and rumination; believing in uniqueness is accompanied by depression and suicidal thoughts that may result from low levels of self-compassion; they finally argue that self-compassion contributes to the development of physiological system in mammals, which guides attachment. Individuals, who have been raised in secure and supportive environments, tend to have higher self-compassion and self-care, and those, who have been raised in insecure, stressful, and threatening environments, tend to treat themselves colder and more critically, and finally, self-compassion causes people to less engage in unethical behaviors (anger and aggression) and feel less discomfort in the face of negative conditions.

In addition, in explaining this finding, we can say that when faced with pain, incompetency, or failure, those with self-compassion, act toward themselves warmly and with a non-judgmental understanding rather than exaggerating the pain and suffering and blaming themselves. Self-compassion implies that flaws, mistakes, imperfection, or dealing with life problems are part of a common human experience; other people, more or less, deal with these in their lives, and the person is not the only one experiencing them. When a person cannot deal with their feelings in a compassionate manner, their feelings will be suppressed and ignored. In contrast, self-compassion involves a balanced approach toward emotions, so that they are experienced completely (Neff, 2003a).

Another finding of the present study indicated that selfcompassion, compared to self-esteem, is more capable of predicting maladaptive cognitive emotion regulation strategies. On the other hand, self-esteem, relative to self-compassion, is a better predictor of three adaptive strategies, including refocus on planning, positive reappraisal, and putting into perspective. This finding does not agree with the previous findings that selfcompassion is a better predictor of mental health than self-esteem. For example, Leary, Tate, Adams, Allen \& Hancock (2007) showed that in embarrassing situations, self-compassion, compared to self-esteem, is related to higher emotional balance.

Neff (2008) showed that in anxiety-eliciting academic situations, self-compassion in contrast to self-esteem, acts as a cushion and protects a person against unpleasant conditions. Self-compassion is also positively related to the use of first-person plural pronouns and social references, such as friends, family, and associations (Rude, Gortner, \& Pennebaker, 2004). In support of this finding, it has been shown that those with higher self-compassion tend to have better psychological health, because in these people, the unavoidable pain and feeling of failure that everyone may experience is not continued due to a cruel self-blame, feeling of isolation, and excessive identification with thoughts and emotions (Neff \& Pommier, 2013). Individuals with high self-compassion solve interpersonal conflicts by considering the needs of themselves and others (Yarnell \& Neff, 2013).

Because self-compassion requires conscious awareness of personal emotions (Bennett-Goleman, 2002), painful feelings are not avoided, but the person faces these feelings with kindness, understanding, and common human feelings; therefore, those with self-compassion can effectively and adaptively manage their negative emotions. As a result, negative emotions are turned into more positive feelings, and the person finds the opportunity to better understand the situation and choose effective strategies for self-regulation (Saeedi, Ghorbani, et al., 2013). Based on what was mentioned, it seems reasonable to consider self-compassion as a construct with an effective role in the use of adaptive emotion regulation strategies.

Self-compassion has similar psychological benefits as self-esteem, but it is related to less negative aspects, such as ego-defensiveness or narcissism (Leary et al., 2007; Neff, 2003a). Neff \& Vonk (2009) found that self-compassion compared to self-esteem, was related to more unconditional and stable feelings. Self-compassion is also a more effective protector against social comparison, rumination, anger, and prejudice. These findings are consistent with the study findings that on the one hand, indicated that self-compassion is a better negative predic- 
tor of maladaptive cognitive emotion regulation strategies, and on the other hand, showed that this construct predicts adaptive cognitive emotion regulation strategies, relatively in the same way as self-esteem does. In other words, not only self-compassion has the benefits of selfesteem, but it is also a better indicator of mental health.

One of the reasons that self-compassion is more beneficial than self-esteem is that it stays stable, even when self-esteem collapses. This means that self-compassion can help individuals overcome self-aversion, without requiring a person to take an unrealistic view of an unpleasant situation (Leary et al., 2007). In addition, selfcompassion is based on self-importance, self-care, and nonjudgmental understanding, but self-esteem is based on positive self-evaluation. Leary (2007) states that the unpleasant feelings resulting from self-evaluation are mainly because severely inflated ego may sometimes become a curse. The anxiety of this condition can elicit feelings, such as shame that results from a negative general self-evaluation and perceiving the danger of social isolation (Tangney, 2003). Self-compassion may help reduce self-evaluation anxiety, because self-kindness and understanding the incomplete human nature can decrease the persistent need for positive evaluation. In contrast, a high self-esteem can reduce protection against self-evaluation anxiety (Leary, Barnes, Griebel, Mason, \& McCormack, 1987).

Moreover, drawing from the social mentality theory, Gilbert (2005) suggests that self-compassion deactivates the threat system and replaces it with the soothing system. In contrast, self-esteem is based on superiority/ inferiority evaluation and is related to the activation of Dopamine (Gilbert \& Irons, 2005). The soothing quality of self-compassion leads to a higher capacity for intimacy, effective emotion regulation, and a better adjustment to the environment (Gilbert, 2005). It is worthwhile to note that self-compassion and self-esteem scores are highly correlated. Neff (2003a) found a high correlation between the scores on the SCS and the RSES $(r=0.59$ $\&$ 0.62). This relationship indicates that individuals with a higher level of self-compassion, feel more positively about themselves, and those with a lower level of self-compassion, perceive themselves more negatively; however, these two are conceptually different constructs. When self-esteem is controlled, self-compassion remains a strong predictor of depression and anxiety. Neff (2003a) showed that self-esteem was significantly associated with narcissism, but self-compassion was not.

In summary, the study results indicate that both selfcompassion and self-esteem have a positive relation- ship with cognitive emotion regulation strategies and a negative relationship with maladaptive strategies. However, self-compassion is a good indicator of mental health, and compared to self-esteem considered for years as an important criterion for mental health, it can be regarded as a better predictor of mental health. When faced with difficulties and conflicts, individuals with a high self-compassion avoid judgmental perceptions and try to use self-regulation strategies that, on one hand, reduce the negative effects of a stressful situation, and on the other hand, improve the person's mental health, as a result of controlling or managing the situation. In these people, having a non-judgmental self-perception, feelings of common humanity, and a balanced approach toward emotions, serve as a shield against an unpleasant situation and allow the person to consider the situation as a life experience rather than a stressful situation. In contrast, self-esteem, due to its positive relationship with performance anxiety, often leads a person to choose strategies that reduce their ability to deal with negative situations. Therefore, self-compassion has to be regarded as an important indicator of mental health.

The present study had several limitations, including the use of a convenient sampling method, a limited sample of students, and self-report questionnaires. Using a convenient sampling method can create problems in terms of generalizability of the data. Self-report questionnaires are subject to self-serving biases as individuals with a high self-esteem that may sometimes lead to narcissism, are very capable of making a good first impression (Paulhus, 1998) and have a strong tendency to deceive themselves and others (Campbell, Rudich, \& Sedikides, 2002); this kind of bias can make an important limitation for the self-report instruments used in this study.

We suggest future studies to examine the mediating role of cognitive processes in the relationship between self-compassion and mental health indicators, in order to determine how self-compassion is related to health behaviors. It is also suggested that future studies should use other methods, such as emotion and stress induction techniques, behavioral observation, priming for emotion regulation in laboratory settings, and also using a voice recorder or other programs for analyzing psychological texts, such as the Linguistic Inquiry and Word Count (LIWC), to overcome the limitations of self-report techniques and to get a deeper insight into the study variables. Moreover, using other methodologies, such as qualitative studies can lead to a deeper understanding of the mental processes involved in self-compassion and emotion regulation strategies. Furthermore, According to the study results, it is suggested that mindfulness and 
compassion in educational courses and interventions can help to improve the mental health of the society.

\section{Acknowledgments}

This research did not receive any specific grant from funding agencies in the public, commercial, or not-for profit sectors. Finally, we wish to sincerely thank all the participants in the present study and all those who supported us in this project, especially Ms. Mohammadkhani.

\section{Conflict of Interest}

The authors declared no conflicts of interest.

\section{References}

Aalsma, M. C., Lapsley, D. K., \& Flannery, D. J. (2006). Personal fables, narcissism, and adolescent adjustment. Psychology in the Schools, 43(4), 481-91. doi: 10.1002/ pits.20162

Aberson, C. L., Healy, M., \& Romero, V. (2000). Ingroup bias and self-esteem: A meta-analysis. Personality and Social Psychology Review, 4(2), 157-73. doi: 10.1207/s15327957pspr0402_04

Afshary, M., Babakhani, N., Ahmadi, A., Shamseddinilorry, S. (2016). Comparison of the rate of self-esteem, self-efficacy \& self-regulation in opiates \& stimulant substance dependents with normal people. Iranian Journal of Forensic Medicine, 22(1), $15-22$.

Alavinezhad, R., Mousavi, M., \& Sohrabi, N. (2014). Effects of art therapy on anger and self-esteem in aggressive children. Procedia - Social and Behavioral Sciences, 113, 111-7. doi: 10.1016/j. sbspro.2014.01.016

Bargh, J. A., \& Williams, L. E. (2007). The nonconscious regulation of emotion. Handbook of Emotion Regulation, 1, 429-45.

Bennett Goleman, T. (2002). Emotional alchemy: How the mind can heal the heart. New York: Three River Press.

Besharat, M. (2009). [A primary examination of psychometric properties of the cognitive emotion regulation questionnaire. Research project (Persian)]. Tehran: University of Tehran.

Besharat, M., Bazzazian, S. (2014). [Psychometric properties of the Cognitive Emotion Regulation Questionnaire in a sample of Iranian population (Persian)]. Journal of Shahid Beheshti School of Nursing $\mathcal{E}$ Midwifery, 24(84), 61-70.

Bushman, B. J., \& Baumeister, R. F. (1998). Threatened egotism, narcissism, self-esteem, and direct and displaced aggression: Does self-love or self-hate lead to violence. Journal of Personality and Social Psychology, 75(1), 219-29. doi: 10.1037/00223514.75.1.219

Bushman, B. J., \& Thomaes, S. (2012). When the narcissistic ego deflates, narcissistic aggression inflates. The Handbook of Narcissism and Narcissistic Personality Disorder, 319-29. doi: 10.1002/9781118093108.ch28
Byrne, B. M. (1983). Investigating measures of self-concept. Measurement \& Evaluation in Guidance, 16(3), 115-26.

Campbell, W. K., Rudich, E. A., \& Sedikides, C. (2002). Narcissism, self-esteem, and the positivity of self-views: Two portraits of self-love. Personality and Social Psychology Bulletin, 28(3), 358-68. doi: 10.1177/0146167202286007

Cramer, P., \& Jones, C. J. (2008). Narcissism, identification, and longitudinal change in psychological health: Dynamic predictions. Journal of Research in Personality, 42(5), 1148-59. doi: 10.1016/j.jrp.2008.02.008

Dogan, T., Totan, T., \& Sapmaz, F. (2013). The role of self-esteem psychological well-being, emotional self-efficacy, and affect balance on happiness: A path model. European Scientific Journal, 9(20), 31-42.

Firoozi, M. (2010). Examination of the relationship between emotion regulation strategies and adjustment with childhood cancer $(\mathrm{PhD}$ dissertation). Tehran: University of Tehran.

Forrester, R. L., Slater, H., Jomar, K., Mitzman, S., \& Taylor, P. J. (2017). Self-esteem and non-suicidal self-injury in adulthood: A systematic review. Journal of Affective Disorders, 221, 172-83. doi: 10.1016/j.jad.2017.06.027

Fosco, G. M. (2008). Beyond the parent-child dyad: Testing family systems influences on children's emotion regulation (PhD Dissertation). Milwauke, Wiscansin: Marquette University.

Freire, T., \& Tavares, D. (2011). Influence of self-esteem and emotion regulation in subjective and psychological well-being of adolescents: contributions to clinical psychology. Archives of Clinical Psychiatry (São Paulo), 38(5), 184-8. doi: 10.1590/S010160832011000500003

Garnefski, N., Kraaij, V., \& Spinhoven, P. (2001). Negative life events, cognitive emotion regulation and emotional problems. Personality and Individual Differences, 30(8), 1311-27. doi: 10.1016/s0191-8869(00)00113-6

Garnefski, N., Legerstee, J., Kraaij, V., van den Kommer, T., \& Teerds, J. (2002). Cognitive coping strategies and symptoms of depression and anxiety: A comparison between adolescents and adults. Journal of Adolescence, 25(6), 603-11. doi: 10.1006/jado.2002.0507

Garnefski, N., Teerds, J., Kraaij, V., Legerstee, J., \& van den Kommer, T. (2004). Cognitive emotion regulation strategies and depressive symptoms: differences between males and females. Personality and Individual Differences, 36(2), 267-76. doi: 10.1016/s0191-8869(03)00083-7

Ghorbani, N., Watson, P. J., Chen, Z., \& Norballa, F. (2012). Selfcompassion in Iranian muslims: Relationships with integrative self-knowledge, mental health, and religious orientation. International Journal for the Psychology of Religion, 22(2), 106-18 doi: 10.1080/10508619.2011.638601

Gilbert, P. (2005a). Compassion and cruelty: A biopsychosocial approach. In P. Gilbert (Ed.), Compassion: Conceptualisations, research and use in psychotherapy (pp. 9-74). London: Routledge.

Gilbert, P., \& Irons, C. (2005). Focused therapies and compassionate mind training for shame and self-attacking. In P. Gilbert (Ed.), Compassion: Conceptualisations, Research and Use in Psychotherapy (pp. 263-325). London: Routledge.

Gilbert, P., \& Procter, S. (2006). Compassionate mind training for people with high shame and self-criticism: Overview and 
pilot study of a group therapy approach. Clinical Psychology $\mathcal{E}$ Psychotherapy, 13(6), 353-79. doi: 10.1002/cpp.507

Goodall, K. (2015). Individual differences in the regulation of positive emotion: The role of attachment and self esteem. Personality and Individual Differences, 74, 208-13. doi: 10.1016/j. paid.2014.10.033

Gray Little, B., Williams, V. S. L., \& Hancock, T. D. (1997). An item response theory analysis of the rosenberg self-esteem scale. Personality and Social Psychology Bulletin, 23(5), 443-51. doi: 10.1177/0146167297235001

Hassani, J. (2010). The psychometric properties of cognitive emotion regulation questionnaire. Clinical Psychology, 2(3), 73-83.

James, W. (1892). Text-book of Psychology. Basingstoke: Macmillan.

Joshanloo, M., \& Ghaedi, G. (2008). Reinvestigation of the reliability and validity of the rosenberg self-esteem scale in Iran. Daneshvar Raftar, 1(31), 49-56.

Leary, M. R., \& Downs, D. L. (1995). Interpersonal functions of the self-esteem motive. In M. H. Kernis (Ed.), Efficacy, agency, and self-esteem (pp. 123-44). New York: Springer.

Leary, M. R., Barnes, B. D., Griebel, C., Mason, E., \& McCormack, D. (1987). The impact of conjoint threats to social and self-esteem on evaluation apprehension. Social Psychology Quarterly, 50(4), 304. doi: 10.2307/2786815

Leary, M. R., Tate, E. B., Adams, C. E., Batts Allen, A., \& Hancock, J. (2007). Self-compassion and reactions to unpleasant self-relevant events: The implications of treating oneself kindly. Journal of Personality and Social Psychology, 92(5), 887-904. doi: $10.1037 / 0022-3514.92 .5 .887$

Neff, K. (2003a). Self-compassion: An alternative conceptualization of a healthy attitude toward oneself. Self and Identity, 2(2), 85-101. doi: $10.1080 / 15298860309032$

Neff, K. D. (2003b). The development and validation of a scale to measure self-compassion. Self and Identity, 2(3), 223-50. doi: $10.1080 / 15298860309027$

Neff, K. D. (2008). Self-compassion: Moving beyond the pitfalls of a separate self-concept. In H. A. Wayment \& J. J. Bauer (Eds.), Decade of Behavior: Transcending Self-Interest: Psychological Explorations of the Quiet Ego (pp. 95-105). Massachusetts: American Psychological Association. doi: 10.1037/11771-009

Neff, K. D. (2009). The role of self-compassion in development: A healthier way to relate to oneself. Human Development, 52(4), 211-14. doi: 10.1159/000215071

Neff, K. D. (2011). Self-compassion, self-esteem, and well-being. Social and Personality Psychology Compass, 5(1), 1-12. doi: 10.1111/j.1751-9004.2010.00330.x

Neff, K. D., \& Pommier, E. (2013). The relationship between selfcompassion and other-focused concern among college undergraduates, community adults, and practicing meditators. Self and Identity, 12(2), 160-76. doi: 10.1080/15298868.2011.649546

Neff, K. D., \& Vonk, R. (2009). Self-compassion versus global selfesteem: Two different ways of relating to oneself. Journal of Personality, 77(1), 23-50. doi: 10.1111/j.1467-6494.2008.00537.x
Neff, K. D., Kirkpatrick, K. L., \& Rude, S. S. (2007). Self-compassion and adaptive psychological functioning. Journal of Research in Personality, 41(1), 139-54. doi: 10.1016/j. jrp.2006.03.004

Oschsner, K. N., \& Gross, J. J. (2005). The cognitive control of emotion. Trends in Cognitive Sciences, 9(5), 242-9. doi: 10.1016/j.tics.2005.03.010

Paradise, A. W., \& Kernis, M. H. (2002). Self-esteem and psychological well-being: Implications of fragile self-esteem. Journal of Social and Clinical Psychology, 21(4), 345-61. doi: 10.1521/ jscp.21.4.345.22598

Paulhus, D. L. (1998). Interpersonal and intrapsychic adaptiveness of trait self-enhancement: A mixed blessing. Jour nal of Personality and Social Psychology, 74(5), 1197-208. doi: 10.1037/0022-3514.74.5.1197

Peyvastegar, M., Yazdi, M., \& Mokhtari, L. (2011). [The relationship of narcissism, self esteem and aggression among adolescence girls and their comparisons in early, middle and late adolescence (Persian)]. Quarterly Journal of Psychological Studies, 7(1), 127-44. doi: 10.22051/PSY.1970.1560

Rosenberg, M. (1965). Society and the adolescent self-Image. New Jersey: Princeton University Press. doi: 10.1515/9781400876136

Rottenberg, J., \& Gross, J. J. (2007). Emotion and emotion regulation: A map for psychotherapy researchers. Clinical Psychology: Science and Practice, 14(4), 323-8. doi: 10.1111/j.14682850.2007.00093.x

Rude, S., Gortner, E. M., \& Pennebaker, J. (2004). Language use of depressed and depression-vulnerable college students. Cognition \& Emotion, 18(8), 1121-33. doi: $10.1080 / 02699930441000030$

Saeedi, Z., Ghorbani, N., Sarafraz, M. R., \& Sharifian, M. H. (2013). The effect of inducing self-compassion and self-esteem on the level of the experience of shame and guilt. Contemporary Psychology, 8(1), 91-102.

Salehi, A., Mazaheri, Z., Aghajani, Z., \& Jahanbazi, B. (2015). Role of cognitive emotion regulation strategies in predicting depression. Knowledge \& Research in Applied Psychology, 16(1), 108-17.

Sedikides, C. (1993). Assessment, enhancement, and verification determinants of the self-evaluation process. Journal of Personality and Social Psychology, 65(2), 317-38. doi: 10.1037/00223514.65.2.317

Sharifibastan, F., Yazdi, S. M., \& Zahraei, S. (2016). The role of cognitive emotion regulation and positive and negative affect in resiliency of women with breast cancer. Iranina Journal of Psychiatric Nursing, 4(2), 28-49. doi: 10.21859/ijpn-04025

Shuman, V., Wagner, U., Walter, H., \& Scherer, K. (2014). The social dimension of emotion regulation. Lausanne: Frontiers Research Topics. doi: 10.3389/978-2-88919-219-9

Tangney, J. P. (2003). Self-relevant emotions. New York: Guilford Press.

Tooby, J., \& Cosmides, L. (2005). Evolutionary psychology: Conceptual foundations. In: D. M. Buss (ed), Handbook of evolutionary psychology. (pp. 5-67). Hoboken, New Jersy: John Wiley.

Wang, X., Chen, Z., Poon, K. T., Teng, F., \& Jin, S. (2017). Selfcompassion decreases acceptance of own immoral behav- 
iors. Personality and Individual Differences, 106, 329-33. doi: 10.1016/j.paid.2016.10.030

Welp, L. R., \& Brown, C. M. (2013). Self-compassion, empathy, and helping intentions. The Journal of Positive Psychology, 9(1), 54-65. doi: 10.1080/17439760.2013.831465

Yamini, M., Tahriri, A. (2005). [Foreign language class anxiety among English learners, and its relationship with self-esteem (Persian)]. Iranian Journal of Applied Linguistics, 9(1), 101-129.

Yarnell, L. M., \& Neff, K. D. (2013). Self-compassion, interpersonal conflict resolutions, and well-being. Self and Identity, 12(2), 146-59. doi: 10.1080/15298868.2011.649545

Zare, N., Daneshpajooh, F., Amini, M., Razeghi, M., \& Fallahzadeh, M. H. (2007). The relationship between self-esteem, general health and academic achievement in students of Shiraz University of Medical Sciences. Iranian Journal of Medical Education, 7(1), 59-67. 